INFORMAL LOGIC

XI.2, Spring 1989

\title{
On World Views, Commitment and Critical Thinking
}

\author{
KERRY S. WALTERS Gettysburg College
}

Richard Paul's model of dialectical critical thinking has exerted an immense influence since its introduction some eight years ago-and for good reason. It moved theoretical discussions as well as pedagogical applications of critical thinking away from their earlier atomistic orientations by stressing the crucial roles of world view assumptions and psychological commitment in the construction and evaluation of arguments. In doing so, it weaned critical thinking of its totalizing fidelity to a rarified (and often incredibly tedious) concentration upon the mechanically logical analysis of isolated arguments, nudging it instead towards a pedagogical approach which underscored the "logic of life", significance of thinking skills instruction. For all this, teachers of critical thinking should be profoundly grateful. I, at least, am.

Notwithstanding its very real merits, however, Paul's analysis of the relationship between world view commitments and disagreements raises some philosophical perplexities which, surprisingly, generate doubt about the value and even possibility of critical thinking itself. These perplexities are suggested by the following three questions, each of which I examine in this essay. (1) Is critical thinking itself a world view to which certain individuals are committed? (2) Is there a method to meaningfully adjudicate, in a non-question begging way, world view disagreements between individuals uncommitted or in disagreement with the evaluative criteria of critical thinking? (3) Is critical thinking a "closed", system (I'll define this terminology later) which handles disagreement by "explaining it away" '? I suspect the answers to these queries about Paul's dialectical approach to critical thinking, at least as it now stands, are "yes," "no," and "yes". But before I defend this rather unsettling conclusion, let me refresh my readers' memories on the basics of Paul's model.

\section{Dialectical Critical Thinking}

Paul's point of departure is his claim that traditional approaches to critical thinking go wrong by conveying to students the impression that analysis of propositional arguments amounts to little more than the identification of atomic fallacies embedded within them. This strategy, which I elsewhere have referred to as "analytical reductionism", , focuses exclusively upon breaking down arguments into their simplest constituents (premises and conclusions), and then checking for inferential soundness by ferreting out irrelevancies and ambiguities. A semester-long drilling in the mechanical application of this method to problems and arguments which are far removed from the concrete concerns of students tends to impress upon them the conviction that atomistic analysis is all that's required to rationally appraise knowledge claims (McPeck $^{2}$ aptly dubs such a method logical "trivial pursuit"). But according to Paul, this approach promotes the very sophistry, intolerance and sloppy thinking which critical thinking aims to redress. On the one hand, he argues, it provides some students with an easily manipulable tool by which to dogmatically cling to their own beliefs while facilely trashing those of others. On the other, it so disenchants those students 
perceptive enough to see through such sophistic rationalizations that they renounce logical analysis for the sake of appeals to the perhaps less degenerate but more inchoate operations of "faith," "intuition," "feelings," and "higher consciousness"' 3 . In either case, Paul contends that both the true believer and the apostate come out of a critical thinking course without having learned two crucial lessons. First, that a rational person possesses the disposition to objectively and completely evaluate the merits of her own as well as other's arguments. Second, that individual arguments always reflect an überhaupt frame of reference or world view, and that the latter often contains beliefs which are egocentric, sociocentric and self-deceptive in nature. Consequently, mere atomistic analysis (much less a retreat to mysticism) will not do. To evaluate a given argument, objectively and completely, the rational person must be able and willing to examine the total frame of reference of which it is a part. And that involves scrutiny of its logical merits as well as its psychological commitments and ontological/normative convictions.

To avoid these unhappy consequences, Paul defends a "strong sense" 4 or "multilogical"s model of critical thinking which focuses on analyses of world view commitments and disagreements. In doing so, it deliberately highlights issues which concretely engage students. It encourages them to "explicate, understand, and critique their own deepest prejudices, biases, and misconceptions, thereby allowing [them] to discover and contest their own egocentric and sociocentric tendencies" 6 . This approach replaces atomistic with "dialectical/dialogical" analysis, in which arguments are "appraised in relation to counterarguments" ${ }^{\prime 7}$. Such dialectical interplay presumably functions at two different levels. Reasoners judge the strengths or weaknesses of their own arguments by imaginatively comparing them to the best counterarguments they themselves can construct. But they also evaluate the soundness of their arguments by weighing them against the actual counterarguments of other individuals with whom they disagree. In the dialogical give-and-take which operates at either level, participants in dialectical critical thinking come to a better understanding and possible resolution of the causes for their disagreements. Such a rapproachment is made possible through their newly discovered awareness that the world view beliefs which prompted disagreement are in fact based upon nonjustifiable subjectivisms that retard objective appraisal. These subjectivisms can be uncovered and eliminated through an application of the logical principles of analysis and evaluation. Dialectical critical thinking, then, aims to redress the fundamental weakness in people's reasoning: the dogmatic and unreflective tendency to canonize beliefs. This goal, rather than just the simple atomistic sniffing out of logical fallacies, is what instruction in critical thinking should properly aim for. The purpose is not to demolish any and all passionately held convictions to which an individual may be committed. Instead, it is to ensure that the passionate commitments she retains after dialectical analysis are reflective and rational ${ }^{8}$.

\section{Is Critical Thinking a World View?}

If dialectical critical thinking shoots for the resolution of disagreements between world views, the obvious question to ask is what precisely Paul means by a worldview. Unfortunately, the asking is easier then the answering, because in his various discussions of world views Paul employs a rather bewildering array of what he obviously takes to be synonymous locutions. But if we examine the various ways in which he uses the word, I believe we can discover enough family resemblance between them to arrive at a more or less precise definition.

Sometimes Paul refers to world views as "argument networks" or "nexūs" which can be either "articulated" or "unar- 
ticulated"9. Elsewhere he calls them "multiple realities of life" "10. Occasionally they crop up as paradigmatic structures responsible for the "shaping of our concept of things überhaupt, our system of values, meanings, and interpretive schemes" or, similarly, which " "totalize' our experience and bring that world picture to bear on particular dimensions of our lives" 11 . In other instances they emerge as "global perspectives" 12 or "frames of reference"' 13 . Finally, they're also said to be "logical domains," which appear to be language games whose contexts logically fix the meanings of words used by domain participants: 'The category a thing is in is logically dependent upon what it is like, but all things (including conceptual schemes) are like any number of other things (other conceptual schemes for example) in any number of ways and so are in, dependent on our purposes, any number of logical domains" 14 .

Now, how is all this to be understood? What Paul's various locutions seem to suggest is something like the following: a world view is a set of general attitudes and beliefs about the nature of the world, values and methodologies whose particular orientation gives rise to what its defender takes too be a coherent totalization. The überhaupt conceptual scheme of such an orientation, the total nature of which is typically only partially conscious to the world view holder, is expressible through an argument nexus or network. An argument nexus accepts or rejects certain meanings and methodologies according to the logical domain appropriate to the world view it expresses. Consequently, depending upon the language games played by participants in various world views, the connotation of words and criteria of evaluation can differ from one to the next. Because of my world view, for example, "abortion" connotes one set of meanings in my argument nexus. But your world view, insofar as it posits a different überhaupt concept of things, attaches a different and possibly contradictory set.

Two additional features of world views must be kept in mind. First, because they serve as paradigmatic frames of reference by which an individual makes sense (normatively as well as nonnormatively) of her experiences, world views are psychological centers of gravity to which persons are deeply and perhaps passionately committed. They are, in short, forms of life that may to a certain extent be abstractly articulated but more often are simply lived. They are so intimate a part of what a person is that, as Paul correctly points out, it is often quite difficult for their defenders' to recognize forms of self-deception embedded within them.

Moreover, the argument nexūs that reflect world views are properly understood as expressions of überhaupt attitudes rather than specific beliefs. The latter, at least as I'm using the word ${ }^{15}$, are propositional expressions of "fact" that usually lend themselves to some degree of empirical verification, such that it is possible for two individuals who hold conflicting world views to nevertheless hold similar beliefs. Disagreement arises because the involved individuals have an attitudinal disagreement about the interpretation of those beliefs. Their interpretive attitudes, in turn, are determined by the different natures of the logical domains appropriate to their respective world views. Thus it is possible for both you and me to believe that abortion indeed is a fact but, because of our differing frames of reference, to attach opposing clusters of meanings to that belief, normative as well as ontological. I say that abortion is the taking of a person's life (ontological interpretation) and hence ethically unwarranted in most cases (normative interpretation). You concede that abortion is the elimination of life, but not the life of a "person" (ontological interpretation), and hence is ethically acceptable in most cases (normative interpretation). And so on.

I don't want to maintain that this distinction between attitudes and beliefs is a hard and fast one. It is offered only as a general dividing line, and certainly does not 
preclude exceptions. There are occasions, perhaps, in which differences in attitudes can lead to such discrepant interpretations of beliefs as to erode most of the common ground necessary for the meaningful comparison of these beliefs. Similarly_but, I think, less likely - it is possible that the interpretive scheme generated by one world view may be such that its logical domain simply cannot accommodate (that is, its participants, by virtue of their language game, cannot comprehend) some of the propositionally expressible beliefs of another world view. I don't mean to shortchange these possibilities, but only to point out that the argument networks which articulate world views, taken überhaupt, are properly understood as expressing general attitudinal ways of looking at the world. (This point is more readily apparent in the German "Weltanschauung".) It is this difference in interpretive attitudes which enables us to recognize disagreements between conflicting world views. But it is the more or less commonality of specific beliefs which serves as the possibility of inter-world view communication. Without at least that common denominator, world views would be windowless, mute and totally self-absorbed interpretive schemas.

The question now arises as to whether all bodies of knowledge are world view dependent, such that disagreements between them are little more than differences between interpretive attitudes. This is just another way of asking whether knowledge is necessarily perspectival in nature, dependent upon the überhaupt concept of things which individuals by hook or crook have adopted. Paul's discussion of human knowledge at times explicitly reads as if it indeed is to be understood as radically perspectival. He says, for example, that "we do not deal with the world-in-itself but with the world-as-we-define-it in relations to our interests, perspective, and point of view"'16. Or: "As humans we are-first, last, and always-engaged in inter-related projects which, taken as a whole, define our personal 'form of life' in relation to broader 'social' forms. Because we are engaged in some projects rather than others, we organize or conceptualize the world, and our place in it, in somewhat different terms than others do"'17. And: 'Knowledge, rightly understood, is viewed as a distinctive construction [my emphasis] by the knower'"18. Additionally, the various locutions Paul takes as synonyms for world views-" frames of reference," "multiple realities of life," überhaupt interpretive schemes," "logical domains"-clearly smack of epistemological perspectivism. Moreover, if it is the case, as Paul claims it is, that arguments are always reflections of contextual world view attitudes, it would seem to follow that the conceptual structures assumed by any given argument, as well as the standards of appraisal accepted by the proponent of that argument, are likewise attitudinal perspectives generated by the logical domain of the world view whence they emerge.

Two conclusions, I believe, follow from these considerations. The first is that it is inappropriate to claim that one argument nexus expression of a world view is logically sounder than another (much less than one is correct and one incorrect). We may say that one interpretive attitude is more interesting than another, or that one offers more psychological comfort than another. But if all world views and their constitutive bodies of knowledge are perspectival in nature-that is, express the "world-as-wedefine-it" rather than the "world-initself" - that's about as far as our evaluations can go. And that trivializes the role of critical thinking to little more than a twofold function: checking the internal coherency between propositions on the one hand and subarguments on the other that comprise world view frameworks, and helping individuals to realize that their world views are necessarily perspectival-that is, ego- and sociocentric-in character. There's something to be said, I suppose, in overcoming the self-deceptive presumption that 
the deepest convictions an individual holds are and must be subjective and contextual, but not much. After that's pointed out, there's nothing left for critical thinking to do. It can't resolve disagreements between two or more world views because each, within its own context, is just as good as the next.

This trivialization of critical thinking's role in evaluating world views shouldn't unduly upset us, however, since critical thinking itself-and this is the second conclusion-is likewise the argument nexus expression of a perspectival worldview. It must be, inasmuch as it is a methodology which directly reflects certain assumptions about the nature of knowledge and, less directly, about the nature of reality. As Paul has already pointed out, all such constructs are dependent upon logical domains, and all logical domains are intimately associated with world views. True, the critical thinking world view is one, I suspect, which most of us who regularly read this journal prefer. But given a few accidental changes in the psychological and sociological contexts which shaped our überhaupt attitudinal way of looking at things, we could just as easily, and just as legitimately, prefer readingwell, anything else.

The answer to the first question of whether critical thinking itself is a world view, then, appears to be "yes". It seems clear (as will be pointed out in the next section) that Paul does not want to maintain this ${ }^{19}$. Indeed, he cannot do so and simultaneously continue to argue that the logical technique of dialectical critical thinking encourages a disposition to appraise argument nexus objectively as well as resolve disagreements between conflicting world views. But the way in which he characterizes world views as well as human knowledge undercuts this argument and forces him into a perspectival flybottle. The upshot, then, is that the evaluative standards proper to critical thinking are just one of many ways of looking at the world überhaupt and have no more objective claim on our fidelity than any other. If someone is committed to critical thinking, it's either because she's chosen that commitment or has absorbed it by virtue of the logical domain of which she is a cradle initiate. Moreover, if she's committed to it because she thinks it an objective method for appraising knowledge claims, she's selfdeceived. If she realizes that in fact it is not objective but only perspectival, yet nonetheless retains her commitment to it, her decision seems rather arbitrary. Either way, her position is less than rational. But given the drift of Paul's argument, rationality itself, I suppose, is likewise merely a perspectival attitude. So, once again, there's really little to be upset about.

\section{Can World View Disagreements About Critical Thinking Be Adjudicated?}

The answer to this question has been suggested by the previous section's argument, and will be further explored in the next. But a few specific remarks are in order here.

As I pointed out earlier, Paul does not want to buzz his way into a perspectival flybottle. He means the method of dialectical critical thinking to be an objective way of deciding between world view disagreement, and this entails that it be world view neutral. That such is his aim is clearly indicated in the following passage:

\footnotetext{
... because more than one frame of reference [or world view] is contending for ... construal and settlement, we must somehow 'test' the frames of reference themselves. The only way to test whole frames of reference without begging the question is by setting the frames of reference dialectically against each other so that the logical strength of one can be tested against the logical strengths of the contending others by appealing to standards not peculiar to either. ${ }^{20}$
}

But the suggestion that we can compare the "logical strengths" of two conflicting world views by appealing to standards "not 
peculiar to either," given my earlier conclusion that the logical analysis of critical thinking is itself an attitudinal perspective, is quite puzzling. To use it as an evaluative criterion by which to separate world view sheep and goats raises at least three problems.

First, as I argued earlier, it is difficult to see how the "logical strengths" of world views can be compared in such a way as to reach the conclusion that one is "better" or "more accurate" than another. Since a world view by definition is merely perspectival in nature, the most that a "logical analysis" of it can do is to test for consistency between the subarguments. which constitute its argument nexus expression. But such an analysis is too anemic to resolve world view disagreements except in either a specious or bizarre manner. It might turn out, for example, that such an analysis reveals that world view p's argument nexus is more coherent than world view q's and this in turn might lead to the conclusion that $p$ is sounder, more accurate, than $q$. But unless it is established that the standard of coherency is itself a world view-neutral, objective criterion of evaluation, such an appraisal would be question begging and hence specious. On the other hand, it is quite possible than an analysis of the internal consistency of $p$ and $q$ 's argument nexus would reveal that both are perfectly coherent. In this case, we would be forced to bizarrely conclude that both are equally sound or accurate, notwithstanding the fact that they are quite different and even possibly contradictory.

But, secondly, suppose the participants in any and all possible logical domains somehow contract with one another to accept the logical rules of analysis characteristic of critical thinking as proper trans-world view evaluative criteria. They acknowledge, of course, that critical thinking is itself simply another world view, but mutually agree to "commit" themselves to examine and resolve world view disagreement according to its standards. Further- more, they even argue that their universal stipulation of it as a trans-world view calculus bestows upon it a kind of "pragmatic" objectivity. After all, if every world view adopts the criterion, then it's not "peculiar" to any. Would this release the fly from its bottle?

I doubt it. There are psychological as well as logical problems with this argument. In the first place, Paul has indicated that world views are paradigmatic constructs to which their proponents are passionately, albeit (ideally) rationally committed. Now if the entire set of participants in various logical domains are aware of the fact that their acceptance of critical thinking as a trans-world view evaluative criterion is merely a stipulation (and, moreover, an arbitrary one; after all, they could just as well have stipulated some other criterion or criteria), it's difficult to see how they could be genuinely committed to its use in their respective world views. It is quite possible to be psychologically committed to an erroneous belief one does not know is erroneous. But I doubt whether it's equally possible to be psychologically committed to a belief which one merely pretends is true. On the one hand, if the participants in various logical domains (or, perhaps, their descendants) are passionately committed to critical thinking because they've forgotten it's merely a stipulated criterion, thereby taking it as a genuinely objective one, then their world views are shot through with self-deception and their passionate commitment is irrational. But Paul has already argued that forms of self-deception render world views unsound. In fact, one of the primary goals of his dialectical critical thinking model is to uncover and expunge them.

Moreover, there seems to be no compelling reason why a logical domain participant, even after she's contracted with others to accept critical thinking as a transworld view criterion, cannot simply opt out of the contract at a future date. After all, critical thinking is still just one perspective 
among many, regardless of how many people agree to pretend otherwise. The only arguments that might be offered in response to her apostasy would be prudential, normative or question-begging ones. We might say to her, for instance, "If you opt out of the contract, thereby disavowing the stipulated objectivity of logical consistency and coherency as standards for evaluating argument nexus expressions of world views, no one else will take your world view seriously". Or, alternately, "If you break the contract, thereby disavowing the stipulated objectivity of logical consistency and coherency as standards for the evaluation of argument nexus expressions of world views, you'll be going back on a promise and acting unethically'. Or finally: 'If you opt out of the contract, thereby disavowing the stipulated objectivity of logical consistency and coherency as standards for the evaluation of argument nexus expressions of world views, your decision will be inconsistent with the earlier one you made in contracting with the rest of us. Therefore it's irrational".

But given Paul's perspectival characterization of world views and knowledge, a perfectly reasonably (and, to my mind, perfectly unanswerable) response for our apostate to offer would be "So what? My überhaupt concept of things and values is different from yours. My world view legitimizes breaking promises and doesn't concern itself with logical standards of consistency. Moreover, I couldn't care less about whether or not you take it seriously. I do-in fact, I'm passionately committed to it-and that's all that matters. If you think it's irrational, or unethical, or lacks prudence, that's just because you're judging it from your logical domain. Don't force your world view's standards upon mine!'

This leaves us with a final strategy for escaping from the bottle. It involves the claim that, in actuality, the logical standards of evaluation espoused by critical thinking are world view neutral, and "not peculiar" to any particular frame of reference.
Therefore an appeal to them in the resolution of world view disagreement is not question begging. Consequently, the logical soundness or accuracy of competing argument nexūs can be rationally determined. (This claim is obviously inconsistent with Paul's ubiquitous characterization of all conceptual systems as perspectival, but let's ignore this difficulty for the sake of the argument.)

How could such a claim be defended? By an appeal to experience. The argument would go something like this. It's true, following Paul, that world views are perspectival in nature, and that the argument nexus which express them reflect this contextualism. This means that it is logically possible for there to be as many world views and corresponding argument networks as there are people (notwithstanding a certain degree of belief and attitudinal intersection). But a world view, it will be recalled, is an attempt to totalize one's experiences, ideas and values into a comprehensive system. A necessary condition for achieving comprehensiveness is that the various subarguments which constitute the overall argument nexus display consistency and coherency, and this presupposes that world view holders subject their own argument networks to logical scrutiny. An empirical examination of different world views, moreover, indicates that reflective and articulated ones do accept and operate according to the analytical criteria of critical thinking. Moreover, even those world view holders who claim to reject logical standards in point of fact do not. This is indicated by their concrete behavior in the world, which reflects a lived, even if unarticulated, fidelity to logical rules of inference, evidence assessment, inductive procedures, and so on. Since a world view is preeminently a form of life which reflects an individual's deepest held convictions, and since even those individuals who claim to reject logic display a form of life which belies their disclaimer, they too (albeit unreflectively) accept the operations characteristic of 
critical thinking. Critical thinking's method of logical analysis, consequently, is not peculiar to any particular world view. Instead, it informs all possible ones, and is therefore world view neutral.

Quite frankly, I take this to be a strong argument, or at least stronger than the other ones considered here. But it's not strong enough. Its problem is that it confuses world view beliefs with world view attitudes.

World view beliefs, it will be recalled, are propositional claims which express what their holders accept as relatively uncontentious "facts". These facts can be conceptual or nonconceptual-a point which is reminiscent of Paul's earlier cited discussion of the types of "things" defined by logical domains. Moreover, it is quite possible for conflicting world views to share common sets of beliefs; it is this, in fact, which is the necessary condition for interworld view dialogue. Disagreement between world views, when it arises, does so on the basis of attitudinal differences prompted by the world views' divergent überhaupt concepts of things and values, and expressed through the patterns of their respective argument nexus. Conflicting world view attitudes attach conflicting clusters of meanings to the commonly held belief such that, to appeal to an earlier example, both you and I believe that abortion is a fact about the world in which we live but, because of our divergent world views, assign conflicting ontological and normative interpretations to that belief.

Now, I would agree that it is likely (and, perhaps, even necessary) that all world view totalizations strive for consistency between their subarguments as well as overall coherency. Given the world view drive for comprehensiveness, this seems reasonable, at least when world view expressions are reflectively articulated. But I would also argue that this common denominator is one of belief, not attitude. What I mean is this: even though an examination of conflicting world views probably reveals that a common element in their überhaupt concepts of things is a belief in the necessity of consistency and coherency, the meanings of consistency and coherency, as well as the standards by which their presence or absence is determined, are world view specific. World view A, for example, contains the belief that consistency and coherency are necessary conditions, and interprets them according to the logical rules characteristic of critical thinking because its frame of reference accepts critical thinking. World view $\mathrm{B}$, on the other hand, likewise contains the belief that consistency and coherency are necessary conditions but, because its frame of reference does not accept the logical rules characteristic of critical thinking, interprets them and tests for their presence or absence in a quite different way. Perhaps a concrete example of such a world view will clarify the point.

In a remarkable book entitled Lame Deer Speaks ${ }^{21}$, John Lame Deer, a Sioux medicine man, provides a gripping and at times quite beautiful account of a world view which perhaps is best characterized as "mytho-poetic" in nature. Lame Deer's frame of reference includes any number of beliefs shared by other ways of looking at reality. His world includes concrete "things"' such as people, animals, clouds, mountains and rivers. Moreover, it likewise contains commonly shared normative beliefs: that wanton cruelty is evil, or that helping a person in distress is virtuous. Finally, Lame Deer's überhaupt concept of things strives for a totalizing vision of reality in which specific beliefs are tied together into a comprehensive whole. This implies that he accepts as part of the set of beliefs definitive of his world view the standards of coherency and consistency, as well as tests for their presence or absence in descriptions of his world view.

But the peculiar attitudinal nature of Lame Deer's frame of reference is such that his criteria for establishing coherency and consistency are quite different from the standards accepted by critical thinking. For Lame Deer, reality is multi-layered; the 
divine intersects with the mundane, the corporeal with the spiritual. This is one of the basic convictions of his world view. Because of it, Lame Deer has no patience with logical principles such as the law of identity or the principle of non-contradiction that critical thinking accepts as standards by which to judge coherency of arguments and consistency between propositions. When he sees a thrush in flight, for example, Lame Deer interprets the object as simultaneously both a bird and not-a-bird. It is, from the perspective of his world view, completely and irreducibly a concrete and mortal thrush, but it is also, at one and the same time, completely and irreducibly infinite and eternal spirit - not a manifestation of spirit, mind you, but spirit itself. It would be useless to point out to Lame Deer that an object cannot be both A and not-A. He would simply smile and patiently inform you that such a rule only applies to the "White Man's" way of thinking, not to the Sioux's. If you pressed the point by asking him what evidence he has for presuming that the thrush is both a bird and not-a-bird, he would tell you, quite matter-of-factly, that his evidence is that he sees, meant quite literally, a bird and not-bird. And if, finally, you responded that not everyone sees the same thing when they look at a thrushthat, in fact, most people merely see a thrush, and nothing else- and that consequently what he sees must be egregiously subjective and lacking in objective evidential support, he will inform you that what other people see is no concern of his. Sometimes, in his less patient moods, he will even go so far as to suggest that people who simply see a bird when they look at a thrush are stupid, and do not know how to interpret evidence correctly.

For Lame Deer, then, coherency between propositions and arguments is not determined by the logical principles defended by critical thinking. Instead, it is established according to the überhaupt attitude necessitated by his own visionary logical domain. His world view has little use for inductive rules of logical inference, empirical assessment of evidence, objective verification, or formal logical axioms. Charges of irrelevancy, ambiguity, or outright contradiction do not disturb him, precisely because they reflect interpretations of coherency and consistency which his world view simply doesn't recognize. The reader of Lame Deer's descriptions of reality who accepts critical thinking as her frame of reference may be amused at his quaintness or, alternately, irritated at his disregard of logic. But, for all that, she cannot deny that Lame Deer's world view consistently conforms to the standards of evaluation it recognizes or that, within its own parameters, the picture of reality and way of knowing it defends are coherent. Similarly, Lame Deer is more than willing to acknowledge that the "White Man's" logical world view, within its own context, is likewise coherent and consistent. It's just that his überhaupt world view attitude prevents him from taking seriously the "White Man's" interpretation of what it means to be coherent or consistent ${ }^{22}$.

This brings us back to the argument that the logical analysis endorsed by critical thinking must be world view-neutral because of the a posteriori conclusion that all world views strive for consistency and coherency. From what I've argued, it follows that such an assumption is questionbegging, and errs in failing to distinguish between world view beliefs and attitudes. It may be the case that the totalizing feature of varying world views points to a common belief in coherency and consistency, but this doesn't at all entail that all world views use critical thinking's yardstick of logical analysis in determining their presence or absence. Once again, then, critical thinking seems to reveal itself as an attitudinal world view. The fly is still in the bottle.

The answer to my second question about Paul's model of dialectical critical thinking should now be obvious. That question, recall, was as follows: Is there a means to meaningfully adjucate, in a non-question 
begging way, world view disagreements between individuals committed and individuals uncommitted to or in disagreement with the evaluative criteria of critical thinking? Inasmuch as it has proved impossible to get critical thinking out of the perspectival flybottle into which Paul's analysis of world views and knowledge has shoved it, the answer must be "no". This implies two things. First, as seen in the preceding section, the dialectical examination of two conflicting world views that display fidelity to logical principles within their frames of reference reduces to the trivial testing of the internal coherency of each. Second, as I've argued in this section, the value of dialectical thinking in resolving disagreements between a world view which accepts and a world view which rejects the logical criteria of critical thinking is, for all meaningful purposes, nil. Either the comparison is question-begging, in which case it is logically illegitimate, or it reduces to nothing more than the passive contemplation of two totally different frames of reference, in which case the entire enterprise of critical thinking, dialectical or otherwise, is rendered vapid.

I suspect, however, that there is yet another reason why Paul's dialectical mode of critical thinking is unable to satisfactorily resolve disagreement between a world view which accepts critical thinking and a world view which rejects it. It's to a consideration of that reason that I now turn.

\section{Is Critical Thinking a Closed System?}

Paul argues that critical thinking properly aims at the dialectical investigation and resolution of world view disagreement. As I indicated at the beginning of this essay, one of the merits of his approach is that it takes seriously the psychologisms (egocentrism, sociocentrism and forms of selfdeception) which infiltrate world views and lead to the dogmatic canonization of them by their proponents. This suggests that many world view disagreements arise because individuals have subjected neither their own nor other's frames of reference to reflective scrutiny in order to discover the forms of self-deception which infiltrate them. In addition to subjective and sociocentric sources of problems, argument nexūs expressions of world views are also susceptible, of course, to charges of logical weakness. In short, according to Paul, there are too overlapping sources of world view disagreement: an unreflective and dogmatic commitment to unwarranted biases, and the absence, to one extent or another, of logical propriety in the articulation of their argument nexus. Dialectical critical thinking seeks to resolve disagreements by disclosing both sources through the give-and-take of argument exchange.

But there is another source of world view disagreement that Paul overlooks, one that sheds light not only on the relationship between world views and commitment in general but also, more particularly, upon my claim that Paul's model necessarily trivializes critical thinking by reducing it to a world view attitude which, when applied outside its own logical domain, is either question begging or irrelevant.

In a recent article ${ }^{23}$ which analyzes religious and nonreligious paradigms, Ian S. Markham discusses the causes of disagreement between conflicting world views (or, as he refers to them, "world perspectives"). Markham agrees with Paul's claim that world views attempt to provide comprehensive explanations which reflect their holders' überhaupt concepts of things. But he distinguishes between two types of world view explanations: "open", and "closed".

An open world view, like all world views, is an attitudinal perspective which seeks to weave experience into a harmonious and complete whole. It accepts certain criteria of investigation and adjudication and rejects others in its quest for a comprehensive explanation of things. Naturally, the precise nature of the criteria it en- 
dorses is dependent upon the logical domain through which it determines meaning and value. But an open world view considers the possibility that its particular logical domain is not an exclusive source of comprehension, that there may be conflicting logical domains in other world views which potentially (although not necessarily) offer better or more interesting interpretations. As such, "Two people with open accounts of disagreements has [sic] the most potential for progress [in the resolution of disagreements], because both parties assume that there must be an element of truth in the other's world perspective". They accept the possibility that "every world perspective has both its strong and weak points, and disagreements arise at the weak points of one's world perspective'"24. Open world views strive for comprehensiveness, then, but do not claim to be all-encompassing totalizations. As such, they leave the door open for genuine inter-world view dialogue and disagreement resolution.

But world views with closed explanations are another matter. They do not shoot for mere comprehensiveness; they also claim to be totalizations, insisting that the standards of evaluation appropriate to their logical domains are unquestionably exclusive. Most importantly, a closed world view explanation does not reject a conflicting world view explanation simply because the latter's überhaupt concept of things is not identical to its own. More subtly, it does so because it has built into its own frame of reference "a single factor or group of factors [which] are taken as the explanation for all disagreements"'25. This suggests that closed world view explanations do not simply disagree with dissenting perspectives because they are blinded by psychological forms of self-deception. Rather, they reject dissenting perspectives because, within the überhaupt concepts of things they defend, it is perfectly rational to do so. It is rational because they provide explanations of where and why the dissenting world view necessarily goes wrong. A clash between the proponents of two closed world views, then, is probably incapable of resolution. As Markham says,

It is not that neither will listen to the other, but that each is interpreting the disagreement in accordance with his own world perspective, and this world view provides the explanation why people disagree with it...The reason why so many disagreements are so intractable is simply this: the disagreement is not merely about the best interpretation of the world; each participant is interpreting the fact that the other is disagreeing in a different way. ${ }^{26}$

Examples of world views which, in a perfectly cogent way within the context of their frames of reference, provide explanations of why people disagree with them include, for example, certain forms of psychoanalysis and religious convictions. The first example's überhaupt concept of things has as one of its fundamental elements the argument that human behavior and convictions are largely motivated by unconscious psychological processes. Consequently, it explains away dissent by interpreting the latter as a manifestation of unconscious resistance or denial. Such a response not only demolishes the dissent, at least in the psychoanalytic world view's eyes. It also reinforces confidence in the ubiquitous applicability of its own explanatory frame of reference. It hasn't simply rejected the opposing perspective in an arbitrary or dogmatic fashion. It has done so by explaining why the holders of that perspective are incorrect.

Or consider the closed world view perspective of a dogmatic Christian (this is not to suggest that all Christians are dogmatic, but only that some are or at least can be). An essential feature of her totalized world view is that humans are so tainted by their sinful natures that they can only be "saved" (that is, see the truth of her world view) if they are infused by and redeemed through divine grace. She explains away dissent, in a perfectly cogent way within the context of her frame of reference, by point- 
ing out that people who disagree with her clearly haven't had an experience of saving grace. Once again, her interpretation (and dismissal) of the disagreement between her world view and those of others is not an arbitrary or mysterious one. Her frame of reference enables her to explain why dissenters disagree, and such explanations in turn reinforce the ubiquitous applicability of her world view.

If Markham is correct, then, the sources of world view commitment and disagreement are more subtle than Paul has imagined. One can be committed to a world view because one dogmatically subscribes to deep-seated and self-deceptive biases. But an individual can also be committed, and therefore tolerate no dissent, because the totalizing nature of her world view provides principles which explain away, in a contextually nonarbitrary manner, dissenting perspectives. It will not do for an outsider to claim that appeals to such principles are question begging. The closed world view holder, within the context of her explanatory frame of reference, can justify them.

This renders the possibility of satisfactorily resolving world view disagreements much more problematic than it originally seemed. In a clash between two closed world views, or between an open and a closed one, there seems little likelihood of arriving at a rapproachment. The only way to do so would be to convince the proponent of a closed world view that the objections to it are compelling. But given the fact that her frame of reference adequately explains away those objections while simultaneously reaffirming its own comprehensiveness, there is no cogent reason why she should abandon her position. Such a move, in her eyes, would be irrational ${ }^{27}$.

Now, I've already established that Paul's discussion of world views and knowledge leads to the conclusion that critical thinking likewise has to be a world view. Furthermore, I've shown that in a conflict between two conflicting world views which both subscribe to the logical analysis of critical thinking, the role of critical thinking is reduced to the trivial one of testing for logical coherency between the subarguments in their respective argument nexus. Finally, I've argued that in a disagreement between a world view which accepts and a world view which rejects the logical standards appropriate to critical thinking, the role of critical thinking in resolving the conflict is not merely trivialized but dissolved. This leaves us with one last question: does it follow from Paul's analysis that the critical thinking world view is a closed one, such that it must disagree with and explain away dissenting perspectives even if, outside the context of its own perspectival frame of reference, it has no justification for doing so?

We must, I fear, answer in the affirmative. Paul has argued that the proper approach in evaluating the strengths and weaknesses of argument nexus is defined by the operations of logical analysis. Such analysis, in his estimation, represents an evaluative calculus "not peculiar" to any given world view; consequently, he takes it as world view-neutral. Since it is world view-neutral, it is ubiquitous in application, capable of serving as the critical acid test for any world view expressed by an argument nexus.

Moreover, it readily provides an "explaining away" explanation of why dissenters disagree with it. This explanation is based upon a set of evaluative criteria which, furthermore, are cogent within the context of critical thinking's frame of reference. These criteria maintain that unsound world views and problematic argument nexus are the result of sloppy thinking, which is exemplified either by an unreflective and dogmatic fidelity to psychologisms or by logical errors in the manipulation of analytic rules of inference. Consequently, when the proponent of a dissenting world view rejects the evaluative criteria defended by the critical thinking world view, she does so because she has fallen prey to sloppy thinking. Her illogical 
orientation, in other words, prevents her from seeing that she is illogical-which is to say that she rejects critical thinking because she's not thinking critically. But the critical thinking world view cannot compromise with, much less accept, such a position. Its totalization of the evaluative principles of logical analysis as sufficient means of separating out the sheep from the goats when it comes to argument nexus prohibits such laissez-faire tolerance. Consequently, it must reject world views whose logical domains dissent from its own, relegating them, as Paul does, to the irrational abyss of " feelings," "'intuitions," "faith" and "higher consciousness". Thus John lame Deer's world view is not simply different. It is unsound.

Furthermore, it must be kept in mind that the proponent of the critical thinking world view is not merely intellectually committed to it. Since it, like all world views, is a form of life which serves as an existential center of gravity, she is also passionately, emotionally, committed to it-although, as Paul insists, in a "rational" (that is, critically thoughtful) way:

Only the development of rational passions can prevent our intelligence from becoming the tool of our egocentric emotions and the point of view embedded in them. A passionate drive for clarity, accuracy, and fairmindedness, a fervor for getting to the bottom of things, to the deepest root issues, for listening sympathetically to opposition points of view, a compelling drive to seek out evidence, an intense aversion to contradiction, sloppy thinking, inconsistent application of standards, a devotion to truth as against self-interest-these are essential commitments of the rational person. ${ }^{28}$

This passionate commitment on the part of the proponent of the critical thinking world view to the rational evaluative standards of logical analysis both underscores and reflects the totalized nature of her frame of reference. She is driven, motivated to the center of her existence, by a desire for logical purity and an aversion to logical impropriety. Moreover, since these drives are rational, the implication is that world view holders who have conflicting or contradictory passionate commitments are less than rational or irrational. And this conclusion only further explains, within the context of the critical thinking frame of reference, why and how dissenters go wrong in disagreeing with it.

\section{Conclusion}

If the foregoing analysis of the philosophical perplexities raised by Paul's discussion of world view commitment and disagreement is correct, the necessary conclusion, as indicated at the beginning of this essay, is that his model reduces critical thinking to quite a trivial role in the evaluation of knowledge claims. Now I do not for a moment believe that critical thinking in fact is so anemic (although, as I've argued elsewhere, its logical evaluative criteria are not as ubiquitously applicable as most conventional interpretations would have $\mathrm{it}^{29}$ ). Consequently, I'm more ready to scrap Paul's model than critical thinking in general.

But not all of Paul's model. As I've tried to make clear, dialectical critical thinking has several admirable features. It draws our attention to the fact that putatively objective arguments are often clouded with psychological forms of self-deception whose disclosure is essential for adequate argument appraisal. It reminds us that a genuine logic for life must deal with überhaupt ways of looking at the world which ground the directions of individual arguments and positions. It cautions us against mutating critical analysis by mindlessly and atomistically manipulating it in a sophistic, unreflective way. And it impresses upon us the very real role critical thinking can play in encouraging a Socratic spirit of intellectual curiosity, self-knowing and fairmindedness.

Paul, however, goes too far. It is one thing to claim that knowledge claims and argument nexūs can be discolored by contextually determined perspectival attitudes. 
But it is quite another to argue that knowledge claims and argument nexūs are necessarily perspectival in nature. This is the flybottle Paul has gotten himself into. And, as his model of dialectical critical thinking now stands, I see no way that he can buzz his way out short of tipping over the bottle and smashing it. In light of the foregoing discussion, such a strategy, I would suggest, is not a bad one.

\section{Notes}

1 See, for example, my "Critical Thinking in Liberal Education: A Case of Overkill?'. Liberal Education 72 (1986), pp. 233-244; "Critical Thinking and the Danger of Intellectual Conformity," Innovative Higher Education 11 (1987), pp. 94-102; "On Bullshitting and Brainstorming," Teaching Philosophy 11 (1988), pp. 301-313; and "Critical Thinking in Teacher Education: Towards a Demythologization," Journal of Teacher Education 40 (May-June 1989), pp. 14-19.

2 J.E. McPeck, "Critical Thinking and the 'Trivial Pursuit' Theory of Knowledge," Teaching Philosophy 8 (1985), pp. 295-308.

3 It should be noted that Paul's evidence for whether or not "traditional" pedagogical approaches to critical thinking lead to these unhappy consequences is anecdotal rather than empirically rigorous, and many advocates of critical thinking have accused him of strawmanning. Although my own experience of critical thinking in the classroom leads me to suspect Paul is more correct than not, I do not want to dogmatically insist upon this point. My only purpose here is to explore the philosophical implication of Paul's position, not to test its empirical reliability.

4 R.W. Paul, "Teaching Critical Thinking in the 'Strong" Sense: A Focus on Self-Deception, World Views, and a Dialectical Mode of Analysis," Informal Logic 4 (1982), pp. 3-7.

5 R. W. Paul, "Dialogical Thinking: Critical Thought Essential to the Acquisition of Rational Knowledge and Passions," in J.B. Baron and R. J. Sternberg, eds., Teaching Thinking Skills: Theory and Practice (New York: W. H. Freeman, 1987), pp. 127-148.

6 Ibid., p. 140

7 Paul, "Teaching Critical Thinking in the 'Strong' Sense, p. 3.

8 Paul, "Dialogical Thinking," pp. 141-142.
9 Paul, "Teaching Critical Thinking in the 'Strong' Sense,"' pp. 3, 5.

10 R.W. Paul, “McPeck's Mistakes," Informal Logic 7 (Winter 1985), p.40.

11 Ibid., p. 41.

12 Ibid., p. 42.

13 Paul, "Dialogical Thinking," p. 128.

14 Paul, “McPeck's Mistakes,” p. 40.

15 My distinction is derived in part from Copi's distinction between disagreements in belief and disagreement in attitude. See his Introduction to Logic (New York: Macmillan, 1979), pp. 73-75.

16 Paul, "Dialogical Thinking," p. 131.

17 Paul, "Teaching Critical Thinking in the 'Strong' Sense,' p.4.

18 R.W. Paul, "Bloom's Taxonomy and Critical Thinking Instruction," Educational Leadership 42 (May 11985), p. 39.

19 Harvey Siegel in his Educating Reason: Rationality, Critical Thinking, and Education (New York: Routledge, 1988), pp. 143-144, notes that Paul in conversation has concluded it is logically possible for persons to transcend their world views in order to objectively analyze them, thereby implying that he means dialectical critical thinking to be world view-neutral Unhappily for his model, Paul adds that such an enterprise is "difficult, and perhaps impossible". I should note here that my conclusion in this section that Paul's description of argument nexus and knowledge reduces critical thinking to a world view is likewise suggested by Siegel (p. 14). My analysis, however, explores the criticism more fully than his, and is less sanguine about the possibility of salvaging dialectical critical thinking. Moreover, I feel obliged to mention that my agreement with Siegel in this section (and in this section only) does not imply that I likewise agree with his 
"reasons conception" model of critical thinking. I cannot see that it is the viable alternative to Paul's model Siegel claims it is, and explain why in my "Is There a Strong Sense Critical Thinking?', forthcoming.

20 Paul, "Dialogical Thinking,"' p. 128.

21 John (Fire) Lame Deer and Richard Erdoes, Lame Deer: Seeker of Visions (New York: Washington Square Press, 1972).

21 J.S. Bruner's recent Actual Minds, Possible Worlds (Cambridge, MA: Harvard University Press, 1986), sheds some light upon the natures of world views which disagree about standards of evaluation in its analysis of "narrative" ways of knowing and "paradigmatic"' ways of knowing. In the context of this discussion, Bruner's first type is analogous to that world view which rejects critical thinking. His second type is analogous to that world view which accepts it.

22 Ian S. Markham, "World Perspectives and Arguments: Disagreements About Disagreements," The Heythrop Journal 30 (1989), pp. 1-12.

24 Ibid., pp. 9, 8 .

25 Ibid., p. 7.
26 Ibid., pp. 7.

27 It is worth pointing out here that Markham's general account of closed world views and my specific view of Paul's have some affinities with Popper's critique of nonfalsifiable theoretical models. For Popper's reflections on criteria of the scientific status of a theory, see chapter 1 or his Conjectures and Refutations: The Growth of Scientific Knowledge, (New York: Harper, 1965), especially chapters 1 and 2 . See also chapter 1 of my The Sane Society Ideal in Modern Utopianism: A Study in Ideology (Lewiston, NY: Edwin Mellen, 1989)

28 Paul, "Dialogical Thinking," p. 142.

29 See my "Critical Thinking, Rationality, and the Vulcanization of Students," Journal of Higher Education, in press, as well as "How Critical is Critical Thinking?", The Clearing House, in press, and "Critical Thinking, Logicism, and the Eclipse of Imagining', Journal of Creative Behavior, in press.

KERRY S. WALTERS

DEPARTMENT OF PHILOSOPHY

GETTYSBURG COLLEGE

GETTYSBURG, PA 17325-1486 